\title{
From Racemic to Enantioselective Total Synthesis of Trigonoliimines via Development of an Organocatalytic Enantioselective Michael Addition of $\alpha$-Aryl- $\alpha$-isocyanoacetate to Vinyl Phenyl Selenone
}

\author{
Thomas Buyck§, Qian Wang, and Jieping Zhu* \\ §SCS-DSM Award for best poster presentation
}

\begin{abstract}
Trigonoliimines are hexacyclic bisindole alkaloids isolated recently by Hao and co-workers. A synthesis of $( \pm)$-trigonoliimine B was accomplished in seven steps from simple starting materials featuring the Bischler-Napieralski reaction for closing the seven-membered ring with concomitant formation of an exo-imine. Sulfolane was found to be the solvent of choice for this unprecedented transformation. An organocatalytic enantioselective synthesis of $\alpha, \alpha$ '-disubstituted $\alpha$-amino acids was subsequently developed using methyl $\alpha$-aryl$\alpha$-isocyanoacetates as glycine templates and vinyl phenyl selenone as a Michael acceptor. Using one of this Michael adducts as a starting material, total synthesis of both (+)- and (-)-trigonoliimine A was subsequently realized.
\end{abstract}

Keywords: Asymmetric Michael addition · Bisindole alkaloid · Natural product · Organocatalysis · Selenium . Trigonoliimines

\section{Introduction}

Trigonoliimines were isolated in 2010 by Hao and co-workers from the leaves of Trigonostemon lii Y. T. Chang collected in the Yunnan province of China (Fig. 1). ${ }^{[1]}$ These oxidatively rearranged bisindole alkaloids attracted great attention from the synthetic community because of their unprecedented hexacyclic scaffold and their modest anti-HIV activity (trigonoliimine $\left.\mathrm{A}: \mathrm{EC}_{50}=0.95 \mu \mathrm{g} / \mathrm{mL}, \mathrm{TI}=7.9\right)$. Movassaghi and Han reported a unified strategy allowing them to access all three natural products via enantio-enriched hydroxyindolenines, which were in turn prepared by enantioselective oxidation of bistryptamine. ${ }^{[2]}$ The synthesis also allowed them to revise the absolute configuration of these natural products $\left[\mathrm{C}_{20} S\right.$ for trigonoliimines A (1) and B (2), $\mathrm{C}_{14} S$ for trigonoliimine $\mathrm{C}$ (3)]. Concurrently, Tambar and co-workers published a total synthesis of ( \pm )-trigonoliimine $\mathrm{C}$ based on the same

${ }^{*}$ Correspondence: Prof. Dr. J. Zhu Laboratory of Synthesis and Natural Products Institute of Chemical Sciences and Engineering Ecole Polytechnique Fédérale de Lausanne EPFL-SB-ISIC-LSPN, CH-1015 Lausanne Tel.: +41216939741

E-mail: jieping.zhu@epfl.ch insightful biogenetic hypothesis. [3] Shortly after, Liu and Hao described two different approaches to access the skeletons of trigonoliimines, ${ }^{[4]}$ as well as a short total synthesis of $( \pm)$-trigonoliimine A via a key Strecker/Houben-Hoesch sequence. ${ }^{[5]}$ A modular synthesis of $( \pm)$-trigonoliimine $\mathrm{C}$ has recently been reported by Ramana and Reddy. ${ }^{[6]}$ Shi and co-workers have also communicated an approach to the hexacyclic skeleton of trigonoliimines $\mathrm{A}$ and B. ${ }^{[7]}$ Our group reported a total synthesis of $( \pm)$-triogonoliimine B in 2012 featuring a key Bischler-Napieralski reaction for the construction of the seven-membered ring with the concurrent installation of an exoimine function. ${ }^{[8]}$ Aiming at developing an enantioselective synthesis for this family of bisindole alkaloids, we subsequently developed an organocatalytic enantioselective Michael addition reaction between methyl $\alpha$-aryl- $\alpha$-isocyanoacetate and vinyl phenyl selenone as a general entry to $\alpha$-aryl- $\alpha$-(2'-FG-alkyl)- $\alpha$-amino acids (FG $=$ functional group) and accomplished enantioselective syntheses of both (+)- and (-)-triogonoliimine A using one of the Michael adduct as a starting material.[9]

\section{Synthesis of $( \pm)$-Triogonoliimine B}

Our retro-synthetic analysis of trigonoliimine B (2) is depicted in Scheme 1. We projected to construct the seven-membered ring (ring $\mathrm{C}$ ) by the Bischler-Napieralski (BN) reaction of $4 .{ }^{[10]}$ Although risky, this disconnection was chosen since it would allow the installation of the potentially labile imine function at the same time. The spirolactam 4 could be traced back to azidoester 5 through a sequence of lactamization and

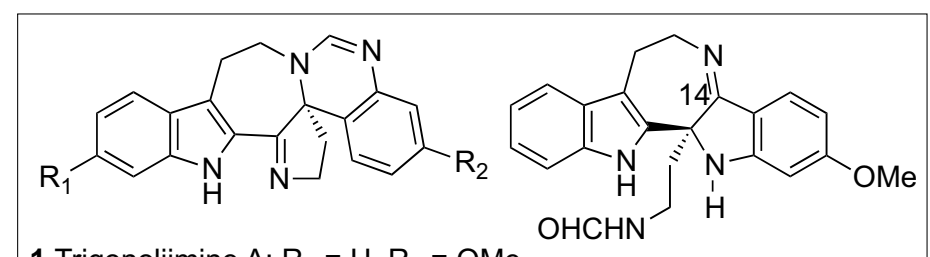

1 Trigonoliimine $A: R_{1}=H, R_{2}=O M e$ 2 Trigonoliimine $B: R_{1}=O M e, R_{2}=H$
3 Trigonoliimine $\mathrm{C}$
Fig. 1. Structure of trigonoliimines. 
amidine formation. The indole unit could be introduced by reductive amination between aldehyde $\mathbf{6}$ and $\alpha, \alpha^{\prime}$-disubstituted amino ester 7 . The latter should be accessible from ethyl $\alpha$-isocyanoacetate $(\mathbf{8})$ by a sequence of arylation and alkylation.

The execution of this synthetic strategy is depicted in Scheme 2. An $\mathrm{S}_{\mathrm{N}} \mathrm{Ar}$ reaction between ethyl isocyanoacetate (8) and 2-fluoronitrobenzene (9) $\left(\mathrm{Cs}_{2} \mathrm{CO}_{3}, \mathrm{DMSO}\right.$, rt) afforded ethyl $\alpha$-(2-nitrophenyl)- $\alpha$ isocyanoacetate (11) in $77 \%$ yield. ${ }^{[11]}$ Alkylation of $\mathbf{1 1}$ with 2-azido iodoethane $(\mathrm{NaH}, \mathrm{DMF}, \mathrm{rt})$ followed by acidic work-up provided the $\alpha, \alpha$-disubstituted$\alpha$-aminoester 7. Reductive alkylation of amine 7 with aldehyde $\mathbf{6}$ under standard conditions $\left[\mathrm{NaBH}(\mathrm{OAc})_{3}, \mathrm{CH}_{2} \mathrm{Cl}_{2}\right.$, rt] afforded the secondary amine $\mathbf{5}$ in an essentially quantitative yield. The one-pot Staudinger reduction of azide $\left(\mathrm{PPh}_{3}\right.$, THF$\mathrm{H}_{2} \mathrm{O}, 60^{\circ} \mathrm{C}$ ) and lactamization under optimized conditions $\left(\mathrm{CaCl}_{2}, \mathrm{MeOH}, 80^{\circ} \mathrm{C}\right)$ provided the desired $\gamma$-lactam 12 in $72 \%$ isolated yield. Reduction of nitro group followed by amidine formation furnished spirolactam 4. To complete the synthesis, our strategy called for the Bischler-Napieralski (BN) reaction for the closure of the sevenmembered ring. However, to the best of our knowledge, no example dealing with the formation of hexahydroazepino[4,5$b$ ]indole skeleton with the concomitant formation of an exo-imine function had been reported at the outset of this work. Initial trials using classical $\mathrm{BN}$ conditions $\left(\mathrm{POCl}_{3}\right.$, toluene, reflux or $\mathrm{POCl}_{3} / \mathrm{P}_{2} \mathrm{O}_{5}$, toluene, reflux) failed to produce the desired product. After extensive survey of reaction conditions, it was found that the $\mathrm{BN}$ reaction of $\mathbf{4}$ proceeded smoothly in sulfolane at $80{ }^{\circ} \mathrm{C}$ to provide trigonoliimine $\mathrm{B}(2)$ in $51 \%$ yield.

Overall, trigonoliimine B (2) was synthesized in seven steps from commercially available starting material with $12 \%$ overall yield. From a synthesis design viewpoint, the use of readily accessible $\alpha, \alpha$ disubstituted $\alpha$-aminoester 7 as a pivotal intermediate and the realization of the unprecedented Bischler-Napieralski reaction are instrumental to the conciseness of the synthetic route.

\section{Development of an Enantio- selective Michael Addition of $\alpha$-Aryl- $\alpha$-isocyanoacetate to Vinyl Phenyl Selenone}

One major drawback of the aforementioned synthesis is the lack of stereocontrol. To address this issue, we became interested in developing a general synthesis of enantioenriched $\alpha$-(2'-FG-alkyl)$\alpha$-aryl- $\alpha$-amino acids. ${ }^{[12]}$ Towards this end, we thought to exploit a catalytic enantioselective Michael addition between $\alpha$-aryl- $\alpha$-isocyanoacetate and vinyl phenyl selenone. ${ }^{[13]}$ The advantages of this approach is that the Michael adduct is easily amenable to further functional group manipulations since i) the isocyano group is readily hydrolyzed to amine under mild acidic conditions and ii) phenyl selenone is an excellent leaving group that is prone to react with a range of nucleophiles. ${ }^{[14]}$ This is in sharp contrast to the Michael adduct resulting from the $\alpha$-cyanoacetate and vinyl phenyl sulfone whose conversion to $\alpha$-amino ester needed a tedious multistep sequence. ${ }^{[15]}$
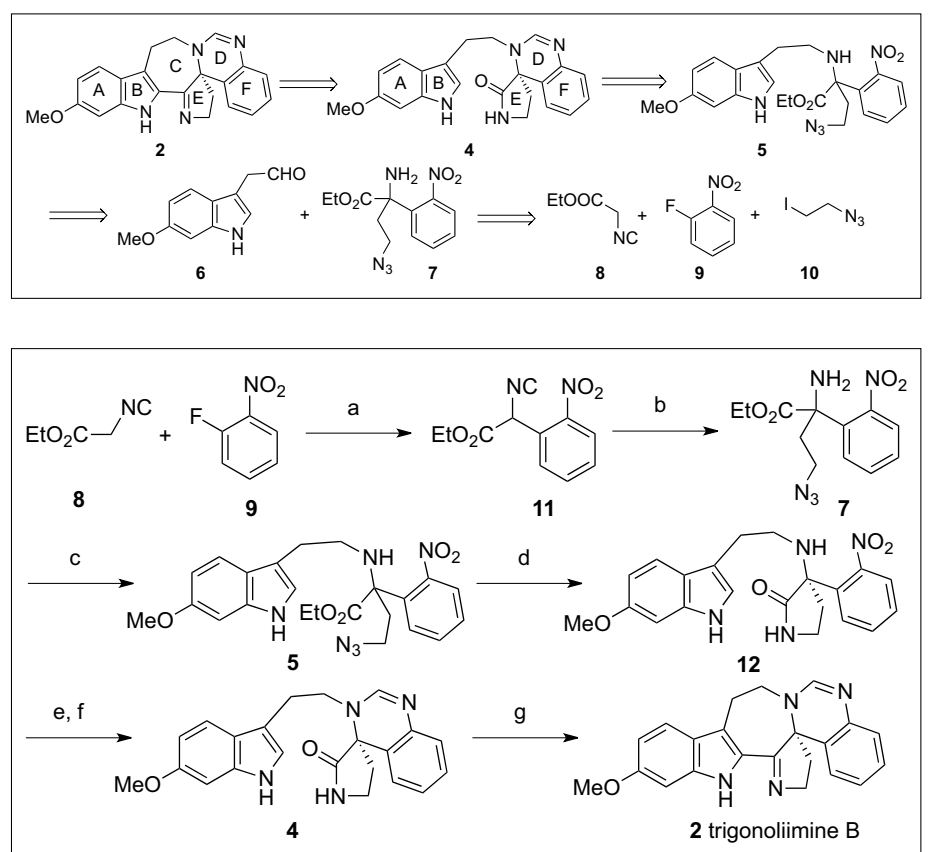

Scheme 1. Retrosynthetic analysis of trigonoliimine $\mathrm{B}$.

Scheme 2. Total Synthesis of trigonoliimine B (2): a) $\mathrm{Cs}_{2} \mathrm{CO}_{3}$, DMSO, $\mathrm{rt}$, $77 \%$; b) $10, \mathrm{NaH}$, DMF, rt, then ethanolic $\mathrm{HCl}(1.25 \mathrm{M}), 70 \%$; c) 6, $\mathrm{NaBH}(\mathrm{OAc})_{3}$, $\mathrm{CH}_{2} \mathrm{Cl}_{2}$, rt, quantitative; d) $\mathrm{PPh}_{3}$, THF$\mathrm{H}_{2} \mathrm{O}, 60^{\circ} \mathrm{C}$, then $\mathrm{CaCl}_{2}, \mathrm{MeOH}, 80^{\circ} \mathrm{C}$, $72 \%$; e) $\mathrm{H}_{2}$, Raney $\mathrm{Ni}, \mathrm{MeOH}, 81 \%$; $)$ $\mathrm{HC}(\mathrm{OMe})_{3}$, PPTS, 60 ${ }^{\circ} \mathrm{C}, 75 \%$; g) $\mathrm{POCl}_{3}$, sulfolane, $80^{\circ} \mathrm{C}$, $51 \%$.
Although alkylation of $\alpha$-isocyanoacetates is well developed for the synthesis of racemic $\alpha, \alpha$-disubstituted $\alpha$-amino acids, ${ }^{[16]}$ there was only one example of enantioselective allylation reported by Ito and Hayashi.[17] Similarly, catalytic enantioselective Michael addition of $\alpha$-isocyanoacetates met only with limited success. Indeed, Lewis acid-catalyzed nucleophilic addition of $\alpha$-isocyanoacetates to polarized double bonds inevitably provided the $[2+3]$ cycloadducts; $[18,19]$ the same trend holds true for organocatalytic processes, ${ }^{[20]}$ with one exception being reported by the group of $\mathrm{Xu}$ and Wang. [21]

Using $\quad \alpha$-phenyl- $\alpha$-isocyanoacetate 13a and vinyl phenyl selenone (14) as test substrates, various cinchona alkaloidderived bifunctional organocatalysts were screened. The results allowed us to draw the following conclusions: i) the presence of an hydrogen bond donor function in $\mathrm{C}\left(6^{\prime}\right)$ of cinchona alkaloids is essential and quinine derivatives having $\mathrm{C}\left(6^{\prime}\right)-\mathrm{OH}$ function displayed better enantio-discriminating power than those bearing 6'-amido and 6'-thioureido groups. ${ }^{[22]}$ However, $\beta$-ICD and its derivatives were ineffective;[23] ii) the alkyl residue introduced to the $\mathrm{C}(9)$ $\mathrm{OH}$ group of quinine influenced also the er of the reaction with $\mathrm{C}(9)-\mathrm{O}^{n} \mathrm{Bu}$ being optimum; iii) the alkyl residue of ester impacted the $e r$ of the reaction with the following trend being clearly observable: methyl ester $>$ ethyl ester $>$ tert-butyl ester; iv) the reaction is best carried out in a nonpolar aprotic solvent in the presence of $4 \AA$ molecular sieves. Overall, the optimum conditions found consisted of performing the reaction of $\mathbf{1 3 a}$ and $\mathbf{1 4}$ in toluene (c $0.25 \mathrm{M}$ ) in the presence of catalyst $\mathbf{1 6}$ ( 0.1 equiv) and molecular sieves at $-40^{\circ} \mathrm{C}$. Under these conditions, the Michael adduct 15a was isolated in $96 \%$ yield with an excellent enantioselectivity (er 97/3, Scheme 3). When quinidine derivative 17, a pseudoenantiomer of 16, was used as a catalyst under otherwise identical conditions, the same reaction afforded ent-15a in quantitative yield with an er of 7.4/92.6.

The scope of this transformation was next investigated by varying the aryl substituent of the methyl $\alpha$-isocyanoacetate. As it is seen from Table 1, both electrondonating group and electron-withdrawing group at ortho, meta or para position of the phenyl were tolerated to deliver the product in high yields with good to excellent enantioselectivities. However, those bearing an electron-donating substituent afforded, in general, the Michael adducts with higher er than those having electron-withdrawing groups. $\alpha$-Heteroaryl- $\alpha$-isocyanoacetates participated in the reaction efficiently to provide adducts in excellent yields and enantioselectivities.

To illustrate the versatility of these 


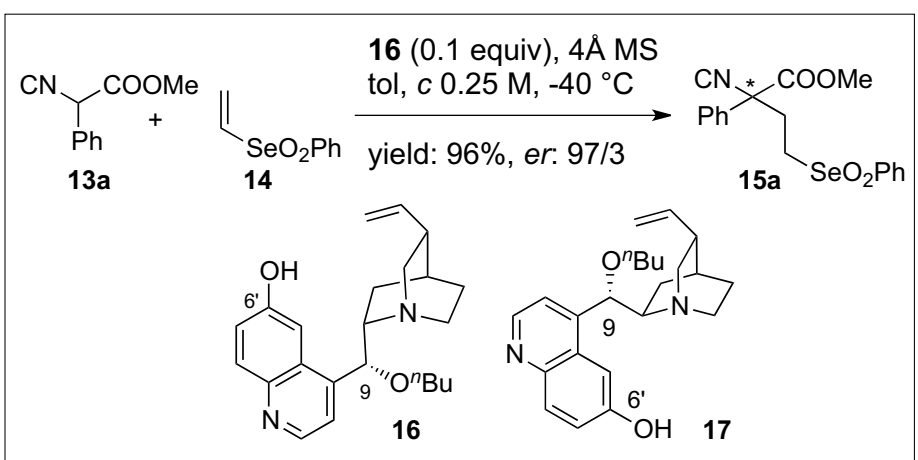

Scheme 3.

Enantioselective Michael addition of $13 a$ to 14.

Table 1. Scope of enantioselective Michael addition.

$$
\mathrm{CN}
$$<smiles>COC(=O)C([Mg])[Al]</smiles>

Entry

1

2

3

4

5

6

7

8

9

10

11

12

13

14
Ar

$\mathrm{Ph}$

4- $\mathrm{MeC}_{6} \mathrm{H}_{4}$

4- $\mathrm{MeOC}_{6} \mathrm{H}_{4}$

$4-\mathrm{FC}_{6} \mathrm{H}_{4}$

$4-\mathrm{BrC}_{6} \mathrm{H}_{4}$

$3-\mathrm{BrC}_{6} \mathrm{H}_{4}$

4- $\mathrm{CF}_{3} \mathrm{C}_{6} \mathrm{H}_{4}$

4- $\mathrm{NO}_{2} \mathrm{C}_{6} \mathrm{H}_{4}$

$$
2-\mathrm{NO}_{2}-4-\mathrm{MeOC}_{6} \mathrm{H}_{3}
$$$$
2-\mathrm{FC}_{6} \mathrm{H}_{4}
$$$$
2-\mathrm{NO}_{2} \mathrm{C}_{6} \mathrm{H}_{4}
$$$$
\text { 2,4-diFC }{ }_{6} \mathrm{H}_{3}
$$

3-furanyl

2-furanyl

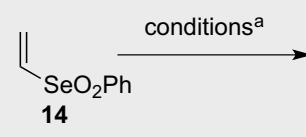

Product

$15 a$

$15 b$

$15 \mathrm{c}$

15d

15 e

$15 f$

$15 \mathrm{~g}$

$15 \mathrm{~h}$

$15 i$

15j

$15 k$

151

$15 \mathrm{~m}$

15n

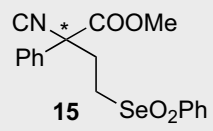

Yield [\%]

96

95

96

92

92

93

96

95

62

96

90

90

94

96 er $^{b}$

97:3

97.9:2.1

96.9:3.1

95.8:4.2

94.5:5.5

90.5:9.5

92.8:7.2

87.3:12.7

93.5:6.5

93.7:6. $3^{\mathrm{d}}$

$89.5: 10.5^{\text {d }}$

91.1:8.9

97.3:2.7

97.1:2.9 a13 (1.5 equiv), 14 (1.0 equiv), 16 ( 0.1 equiv), $4 \AA \mathrm{MS}$, toluene $(c 0.25 \mathrm{M}),-40^{\circ} \mathrm{C}$. betermined by SFC analysis on a chiral stationary phase. ${ }^{\circ}$ Reaction performed at $-10^{\circ} \mathrm{C}$. ${ }^{\mathrm{d}}$ Reaction performed at $-20^{\circ} \mathrm{C}$.

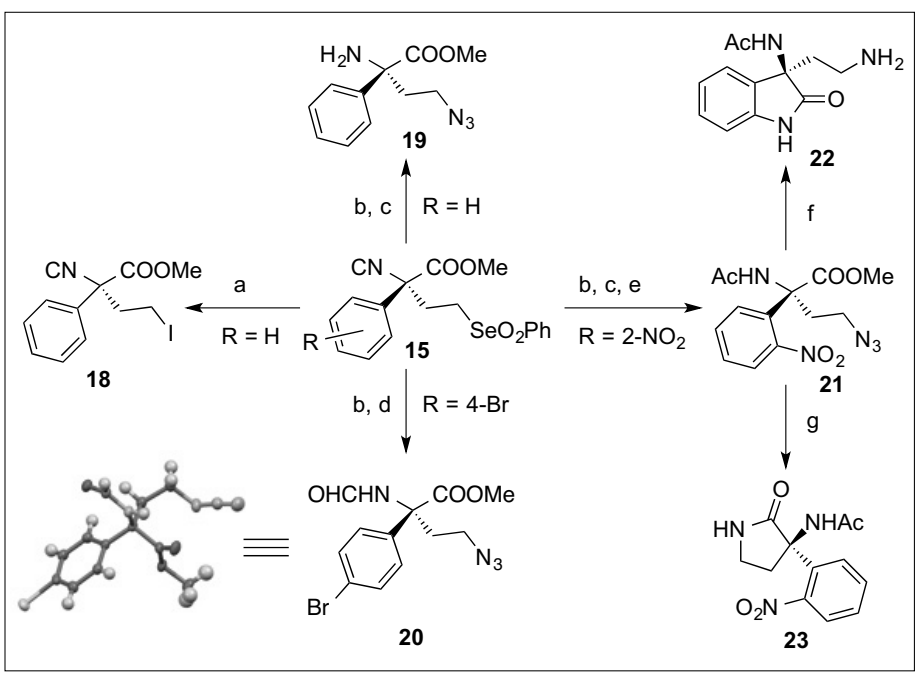

Scheme 4.

Transformations of

Michael adduct 15: a)

$\mathrm{Nal}$, acetone, rt, $99 \%$;

b) $\mathrm{NaN}_{3}$, DMF, 40

${ }^{\circ} \mathrm{C}, 86 \%$ for $19 ; 76 \%$

for 20 ; $69 \%$ for 21 ;

c) $1 \mathrm{~N} \mathrm{HCl}$ in $\mathrm{MeOH}$;

$81 \%$ for $19 ; 81 \%$ for

21; d) $1 \mathrm{~N} \mathrm{HCl}$ in $\mathrm{Et}_{2} \mathrm{O}$,

$70 \%$; e) $\mathrm{Ac}_{2} \mathrm{O}, \mathrm{CH}_{2} \mathrm{Cl}_{2}$,

rt, quant.; f) $\mathrm{H}_{2}$, Raney nickel, $\mathrm{MeOH}$, rt,

$72 \% ; \mathrm{g}) \mathrm{PPh}_{3}$, THF/

$\mathrm{H}_{2} \mathrm{O}(5 / 1), 50^{\circ} \mathrm{C}$,

$77 \%$.

Michael adducts, some basic transformations taking advantage of the reactivity of isocyano and phenyl selenone groups were undertaken. As shown in Scheme 4, treatment of 15a $(\mathrm{R}=\mathrm{H})$ with sodium iodide in acetone at room temperature afforded the iodide $\mathbf{1 8}$ in $99 \%$ yield. Reaction of 15a with sodium azide in DMF at $40{ }^{\circ} \mathrm{C}$ followed by hydrolysis of the isonitrile group to amine $(1 \mathrm{~N} \mathrm{HCl}$ in $\mathrm{MeOH})$ fur- nished $\alpha, \alpha$-disubstituted aminoester 19 in $70 \%$ overall yield. It is interesting to note that the isonitrile can also be hydrolyzed to the $N$-formyl group under milder acidic conditions as demonstrated by conversion of $15 \mathbf{e}(\mathrm{R}=4-\mathrm{Br})$ to $\mathbf{2 0}$. Treatment of $\mathbf{1 5} \mathbf{k}\left(\mathrm{R}=2-\mathrm{NO}_{2}\right)$ with sodium azide followed by hydrolysis of the isocyano group and $\mathrm{N}$-acetylation of the resulting primary amine afforded compound $\mathbf{2 1}$. Hydrogenation of $21\left(\mathrm{H}_{2}\right.$, Raney $\left.\mathrm{Ni}\right)$ directly afforded the 3-acetamido-3'-(2-aminoethyl) oxindole 22 (72\% yield) resulting from the chemoselective lactamization of the aniline nitrogen. On the other hand, selective reduction of azido group under Staudinger conditions $\left(\mathrm{PPh}_{3}, \mathrm{THF}-\mathrm{H}_{2} \mathrm{O}\right.$, $50{ }^{\circ} \mathrm{C}$ ) provided the 2,2-disubstituted pyrrolidinone 23. Both heterocycles are important building blocks in the synthesis of natural products and drug candidates.

\section{Total Synthesis of (+)- and (-)-Trigonoliimine A}

With the above methodology in hand, an enantioselective total synthesis of (+)-trigonoliimine A was accomplished as shown in Scheme 5. Reaction of methyl $\alpha$-(4-methoxy-2-nitrophenyl)- $\alpha$ isocyanoacetate (25), prepared by $\mathrm{S}_{\mathrm{N}} \mathrm{Ar}$ reaction between 8 and 24, with vinyl phenyl selenone under our optimized conditions delivered the adduct $(R)-\mathbf{1 5 i}$ (62\% yield, $e r=93.5 / 6.5)$. Displacement of selenonyl group by azide followed by hydrolysis of isocyanide under mild acidic conditions delivered the enantioenriched quaternary aminoester 27 in $94 \%$ yield over two steps. Reductive alkylation of 27 with 2-(1H-indol-3-yl)acetaldehyde (6) provided 28. Staudinger reduction of azide followed by spontaneous cyclization afforded $\gamma$-lactam 29 in $78 \%$ yield. Reduction of the nitro group in $\mathbf{2 9}$ afforded aniline $\mathbf{3 0}$ that, upon reaction with trimethyl orthoformate, was converted to spirolactam 31. Finally, the Bischler-Napieralski reaction of $\mathbf{3 1}$ under carefully optimized conditions [sulfolane, $c 0.025 \mathrm{M}, \mathrm{POCl}_{3}$ (40.0 equiv), 80 ${ }^{\circ} \mathrm{C}, 70 \mathrm{~h}$ ] afforded the (+)-trigonoliimine A [(+)-1a] in 54\% yield. All spectroscopic data for our synthetic product are in perfect match with those reported in the literature. The sign of the specific rotation of our synthetic sample $\left([\mathbf{a}]_{\mathrm{D}}+225(c 0.3\right.$, $\mathrm{CHCl}_{3}$ ), er 92/8) is opposite to that of Movassaghi's synthetic compound ([a $]_{\mathrm{D}}$ -294 (c 0.24, $\mathrm{CHCl}_{3}$ ), er 97/3) indicating the $(R)$-configuration at $\mathrm{C}(20)$ for our synthetic sample. Following exactly the same synthetic sequence using quinidine derivative 17 as a bifunctional catalyst, (-)-trigonoliimine A [(-)-1a] ([a $]_{\mathrm{D}}-189$, (c 0.29, $\mathrm{CHCl}_{3}$ ), er 86.5/13.5) was synthesized in $6.8 \%$ overall yield. 


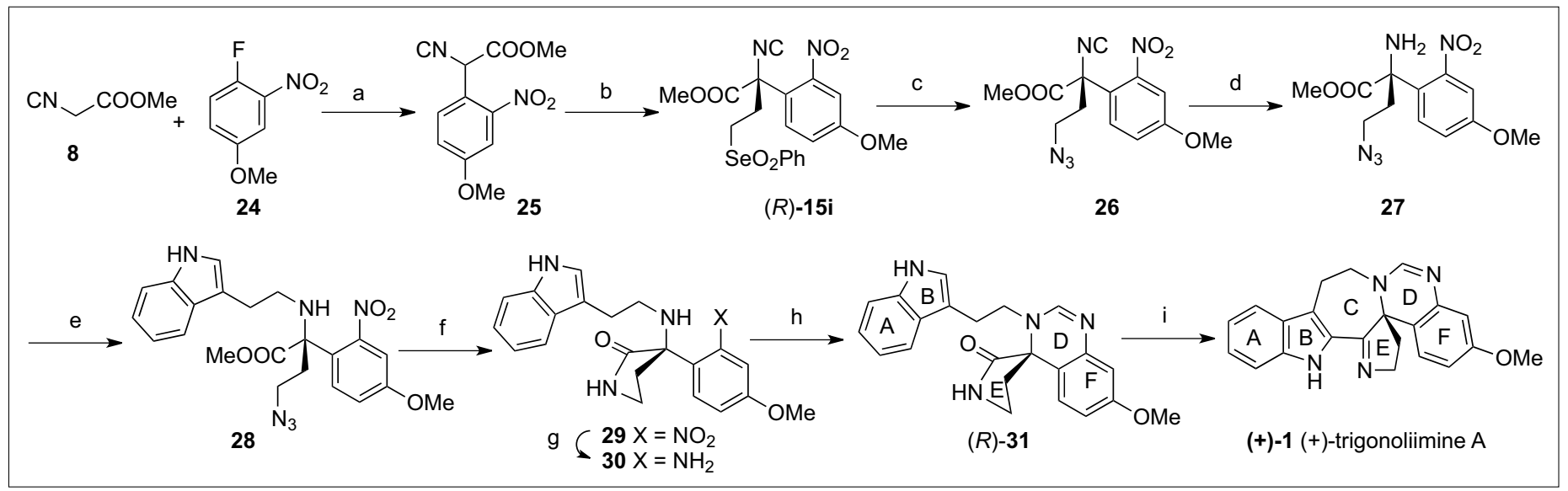

Scheme 5. Total synthesis of (+)-trigonoliimine $\mathrm{A}(\mathbf{1})$ : a) $\mathrm{Cs}_{2} \mathrm{CO}_{3}\left(1.5\right.$ equiv), DMSO, 76\%; b) 14, 16 (0.1 equiv), toluene, $4 \AA$ MS, $-10{ }^{\circ} \mathrm{C}, 62 \%$, er 93.5/6.5; c) $\mathrm{NaN}_{3}$, DMF, rt, 94\%; d) $\mathrm{HCl}, \mathrm{MeOH}$, quantitative; e) 6, $\mathrm{NaBH}(\mathrm{OAc})_{3}, \mathrm{CH}_{2} \mathrm{Cl}_{2}, 73 \%$; f) $\mathrm{PPh}_{3}, \mathrm{THF} \mathrm{H}_{2} \mathrm{O}, 60{ }^{\circ} \mathrm{C}, 78 \%$; g) $\mathrm{H}_{2}, \mathrm{Raney} \mathrm{Ni,} \mathrm{MeOH}$, rt, 84\%; h) PPTS, $\mathrm{HC}(\mathrm{OMe})_{3}, 60^{\circ} \mathrm{C}, 66 \%$; i) $\mathrm{POCl}_{3}$ (40.0 equiv), sulfolane, $c 0.025 \mathrm{M}$, $80{ }^{\circ} \mathrm{C}, 54 \%$.

\section{Conclusion}

In summary, we have accomplished a highly efficient total synthesis of ( \pm )-trigonoliimine B (2) in seven steps from commercially available ethyl $\alpha$-isocyanoacetate (8) and 2-fluoro-nitrobenzene (9) with an overall yield of $12 \%$. The $\alpha, \alpha$-disubstituted amino ester $\mathbf{5}$ was a pivotal intermediate since it allowed us to construct the central tricyclic C-D-E rings in a straightforward manner. Additional features of this synthesis included the use of sulfolane as solvent for the $\mathrm{BN}$ reaction that led to the formation of a seven-membered ring with concurrent creation of an exo imine function. We believed that this solvent could find applications in performing Bischler-Napieralski reactions that are difficult to realize otherwise. Stimulated by the synthetic importance of $\alpha-\left(2^{\prime}-F G-\right.$ alkyl)- $\alpha$-aryl- $\alpha$-amino acids (FG $=$ functional group), an organocatalytic enantioselective synthesis of $\alpha, \alpha^{\prime}$-disubstituted $\alpha$-amino acids was subsequently developed allowing the realization of enantioselective syntheses of both (+)- and (-)-trigonoliimine A (1). Therefore, the present work clearly illustrated the synergism between methodological development and targetoriented synthesis.[24]

\section{Acknowledgments}

T. B. would like to cordially thank DSM and Swiss Chemical Society for the DSM-SCS award. We are grateful to EPFL, Swiss National Science Foundation (SNSF), the COST action (CM0905) and Swiss State Secretariat for Education and Research (SER) for financial support.

Received: January 10, 2014

[1] C.-J. Tan, Y.-T. Di, Y.-H. Wang, Y. Zhang, Y.-K. Si, Q. Zhang, S. Gao, X.-J. Hu, X. Fang, S.-F. Li, X.-J. Hao, Org. Lett. 2010, 12, 2370.
[2] a) S. Han, M. Movassaghi, J. Am. Chem. Soc. 2011, 133, 10768; b) S. Han, K. C. Morrison, P. J. Hergenrother, M. Movassaghi, J. Org. Chem. 2013, 78, 11970.

[3] X. Qi, H. Bao, U. K. Tambar, J. Am. Chem. Soc. 2011, 133, 10050 .

[4] a) S. Liu, X.-J. Hao, Tetrahedron Lett. 2011, 52, 5640; b) J. Qiu, J.-X. Zhang, S. Liu, X.-J. Hao, Tetrahedron Lett. 2013, 54, 300.

[5] B. Zhao, X.-Y. Hao, J.-X. Zhang, S. Liu, X.-J. Hao, Org. Lett. 2013, 15, 528.

[6] B. N. Reddy, C. V. Ramana, Chem. Commun. 2013, 49, 9767.

[7] P. Feng, Y. Fan, F. Xue, W. Liu, S. Li, Y. Shi, Org. Lett. 2011, 13, 5827.

[8] T. Buyck, Q. Wang, J. Zhu, Org. Lett. 2012, 14, 1338.

[9] T. Buyck, Q. Wang, J. Zhu, Angew. Chem. Int. Ed. 2013, 52, 12714.

[10] W. M. Whaley, T. R. Govindachari, Org. React. 1951, 6, 74.

[11] a) D. Bonne, M. Dekhane, J. Zhu, Angew. Chem. Int. Ed. 2007, 46, 2485; b) C. Lalli, M. J. Bouma, D. Bonne, G. Masson, J. Zhu, Chem. Eur. J. 2011, 17, 880 .

[12] Recent reviews on $\alpha, \alpha^{\prime}$-disubstituted $\alpha$-amino acids: a) C. Cativiela, M. D. Díaz-de-Villegas, Tetrahedron Asymmetry 2007, 18, 569; b) H. Vogt, S. Brase, Org. Biomol. Chem. 2007, 5, 406.

[13] a) S. Sternativo, A. Calandriello, F. Costantino, L. Testaferri, M. Tiecco, F. Marini, Angew. Chem. Int. Ed. 2011, 50, 9382; b) S. Sternativo, O. Walczak, B. Battistelli, L. Testaferri, F. Marini, Tetrahedron 2012, 68, 10536; c) F. Marini, S. Sternativo, F. Del Verme, L. Testaferri, M. Tiecco, Adv. Synth. Catal. 2009, 351, 103; d) F. Marini, S. Sternativo, F. Del Verme, L. Testaferri, M. Tiecco, Adv. Synth. Catal. 2009, 351, 1801; e) T. Zhang, L. Cheng, S. Hameed, L. Liu, D. Wang, Y.-J. Chen, Chem. Commun. 2011, 47, 6644.

[14] a) M. Tiecco, A. Carlone, S. Sternativo, F. Marini, G. Bartoli, P. Melchiorre, Angew. Chem. Int. Ed. 2007, 46, 6882; b) M. Tiecco, L. Testaferri, A. Temperini, R. Terlizzi, L. Bagnoli, F. Marini, C. Santi, Org. Biomol. Chem 2007, 5,3510 ; c) For a review, see: F. Marini, S. Sternativo, Synlett 2013, 24, 11.

[15] a) H. Li, J. Song, X. Liu, L. Deng, J. Am. Chem. Soc. 2005, 127, 8948; b) H. Li, J. Song, L. Deng, Tetrahedron 2009, 65, 3139.

[16] S. Kotha, S. Halder, Synlett 2010, 337.

[17] Y. Ito, M. Sawamura, M. Matsuoka, Y. Matsumoto, T. Hayashi, Tetrahedron Lett. 1987, 28,4849 .
[18] a) J. Zhu, Eur. J. Org. Chem. 2003, 1133; b) A. V. Lygin, A. de Meijere, Angew. Chem. Int. Ed. 2010, 49, 9094.

[19] Our group's contribution to the enantioselective addition of isocyanides to aldehydes/imines, see: a) S.-X. Wang, M.-X. Wang D.-X. Wang, J. Zhu, Eur. J Org. Chem. 2007, 4076; b) S.X. Wang, M.-X. Wang, D.-X. Wang, J. Zhu, Org. Lett. 2007, 9, 3615; c) S.-X. Wang, M.-X. Wang, D.-X. Wang, J. Zhu, Angew. Chem. Int. Ed. 2008, 47, 388; d) T. Yue, M.-X. Wang, D.X. Wang, J. Zhu, Angew. Chem. Int. Ed. 2008, 47, 9454; e) T. Yue, M.-X. Wang, D.-X. Wang, G. Masson, J. Zhu, J. Org. Chem. 2009, 74, 8396; f) T. Yue, M.-X. Wang, D.-X. Wang, G. Masson, J. Zhu, Angew. Chem. Int. Ed. 2009, 48,6717 .

[20] a) C. Guo, M.-X. Xue, M.-K. Zhu, L.-Z. Gong, Angew. Chem. Int. Ed. 2008, 47, 3414; b) C, Arróniz, A. Gil-González, V. Semak, C. Escolano, J. Bosch, M. Amat, Eur. J. Org. Chem. 2011, 3755; c) L.-L.Wang, J.-F. Bai, L. Peng, L.-W. Qi, L.-N. Jia, Y.-L. Guo, X.-Y. Luo, X.-Y. Xu, L.-X. Wang, Chem. Commun. 2012, 48, 5175; d) M.-X. Zhao, D.-K. Wei, F.-H. Ji, X.-L. Zhao, M. Shi, Chem. Asian. J. 2012, 7, 2777.

[21] J.-F. Bai, L.-L. Wang, L. Peng, Y.-L. Guo, L.-N. Jia, F. Tian, G.-Y. He, X.-Y. Xu, L.-X. Wang, J. Org. Chem. 2012, 77, 2947.

[22] a) H. Li, Y. Wang, L. Tang, L. Deng, J. Am. Chem. Soc. 2004, 126, 9906; b) H. Li, Y. Wang, L. Tang, F. Wu, X. Liu, C. Guo, B. M. Foxman, L. Deng, Angew. Chem. Int. Ed. 2005, 44, 105; c) F. Wu, H. Li, R. Hong, L. Deng, Angew. Chem. Int. Ed. 2006, 45, 947; d) Y. Wu, R. P. Singh, L. Deng, J. Am. Chem. Soc. 2011, 133, 12458; e) X. Xiao, Y. Xie, C. Su, M. Liu, Y. Shi, J. Am. Chem. Soc. 2011, 133, 12914; f) Y. Wu, L. Deng, J. Am. Chem. Soc. 2012, 134, 14334.

[23] a) Y. Iwabuchi, M. Nakatani, N. Yokoyama, S. Hatakeyama, J. Am. Chem. Soc. 1999, 121, 10219; b) N. Abermil, G. Masson, J. Zhu, J. Am. Chem. Soc. 2008, 130, 12596; c) N. Abermil, G. Masson, J. Zhu, Org. Lett. 2009, 11, 4648; d) N. Abermil, G. Masson, J. Zhu, Adv. Synth. Catal. 2010, 352, 656; e) J.-B. Denis, G. Masson, P. Retailleau, J. Zhu, Angew. Chem. Int. Ed. 2011, $50,5356$.

[24] Other recent examples from our group: a) $\mathrm{T}$. Gerfaud, C. Xie, L. Neuville, J. Zhu, Angew. Chem. Int. Ed. 2011, 50, 3954; b) Z. Xu, Q. Wang, J. Zhu, Angew. Chem. Int. Ed. 2013, 52, 3272; (c) Z. Xu, Q. Wang, J. Zhu, J. Am. Chem. Soc. 2013, 135, 19127. 